\title{
The combined plastic surgery/physical medicine and rehabilitation amputee clinic at the University of Western Ontario
}

\author{
Ryan Neinstein $\mathrm{BSC}^{3}$, A Barry Death MD FRCPC ${ }^{1,3}$, Bing Siang Gan MD PhD FRCSC FACS ${ }^{2,3}$
}

R Neinstein, AB Death, BS Gan. The combined plastic surgery/physical medicine and rehabilitation amputee clinic at the University of Western Ontario. Can J Plast Surg $2008 ; 16(1): 23-26$.

Since the autumn of 2001, a multidisciplinary plastic surgery (PS) and physical medicine and rehabilitation (PMR) outpatient amputee clinic has been in place at St Joseph's Health Centre/Parkwood Hospital in London, Ontario. To date, more than 140 new patients have been seen in combined consultations. The present paper reviews the demographics, interventions and outcomes of the patients seen between 2001 and 2005. The majority of primary PMR patients had problems that prevented optimal use of their lower extremity prostheses. These problems included nonhealing pressure ulcers, infections, painful neuromas, amputation stump shape abnormalities and fixed joint contractures. Most patients had surgical intervention. In terms of overall clinical success, $53 \%$ of the PMR patients and $77 \%$ of the PS patients had their problems resolved. The multidisciplinary collaboration in the PS/PMR outpatient amputee clinic provides a unique service that benefits upper and lower extremity amputees.

Key Words: Amputee clinic; Physical medicine and rehabilitation; Plastic surgery

$\mathrm{T}$ he fundamental principle of plastic surgery (PS) is to restore form and function. Thus, it seems logical that plastic surgeons should be involved with those who have absence of form, such as amputee patients. Many of the problems associated with amputation are related to the shape of the stump, which often requires soft tissue rearrangement. Other stump problems include osteocutaneous adhesions, bony prominences, poor soft tissue coverage or redundant skin, and chronic wounds. Despite an almost natural fit with PS, most amputee care is provided by specialists in physical medicine and rehabilitation (PMR) and not by plastic surgeons. To our knowledge, there is no previous description of a combined PS and PMR clinic devoted to treating amputee patients. At the University of Western Ontario, London, Ontario, such a combined clinic was established in the autumn of 2001. While initially a bimonthly clinic, the demand rose quickly and the clinic became a monthly occurrence. The purpose of the present paper is to review the operative and nonoperative contributions plastic surgeons can make to an amputee clinic and to

\section{Centre de services de chirurgie plastique, de physiatrie et de réadaptation pour amputés à l'University of Western Ontario}

Depuis l'automne 2001, un centre de services pluridisciplinaires externes pour amputés, comprenant la chirurgie plastique $(\mathrm{CP})$, la physiatrie et la réadaptation (PR), a vu le jour au St Joseph's Health Centre/Parkwood Hospital, à London, en Ontario. Jusqu'à maintenant, plus de 140 nouveaux patients ont été examinés dans les différents services de consultation. Le présent article passe en revue les données démographiques, les interventions et les résultats enregistrés entre 2001 et 2005. La majorité des patients vus en PR présentaient des problèmes qui les empêchaient d'utiliser de manière optimale leur prothèse des membres inférieurs. Il s'agissait notamment d'ulcères de compression non cicatrisés, d'infections, de névromes douloureux, d'anomalies relatives à la forme du moignon et de contractures des articulations immobiles. La plupart des patients ont été opérés. En ce qui concerne le taux global de réussite clinique, les problèmes ont été résolus chez $53 \%$ des patients traités en PR et chez $77 \%$ des patients traités en CP. La collaboration pluridisciplinaire au centre de services externes de CP et de PR pour amputés est unique en son genre et elle répond aux besoins particuliers des amputés des membres supérieurs ou inférieurs.

${ }^{1}$ Department of Physical Medicine and Rehabilitation; ${ }^{2}$ Department of Surgery, Division of Plastic Surgery; ${ }^{3}$ Schulich School of Medicine and Dentistry, University of Western Ontario, London, Ontario

Correspondence: Dr Bing Siang Gan, St Joseph's Health Centre, Suite D0-215, 268 Grosvenor Street, London, Ontario N6A 4L6.

Telephone 519-646-6097, fax 519-646-6049, e-mail bsgan@rogers.com 


\section{TABLE 1}

Total new referrals to combined amputee clinic, 2001 to 2005

\begin{tabular}{ll}
\hline & $\mathbf{n ~ ( \% )}$ \\
\hline Primary physical medicine and rehabilitation patients & $78(86)$ \\
Primary plastic surgery patients & $13(14)$ \\
Total & $91(100)$ \\
\hline
\end{tabular}

Total number of new consults in the study period (autumn 2001 to summer 2005) seen in the combined plastic surgery/physical medicine and rehabilitation amputee clinic at Parkwood Rehabilitation Hospital, University of Western Ontario, London, Ontario

elsewhere or who were awaiting surgery at the time the present review was conducted were considered to be treatment failures. Descriptive characteristics were used in the analysis of the data.

\section{Patient population}

\section{RESULTS}

During the study period, a total of 91 patients were given treatment plans in the combined PS/PMR amputee clinic. Of these 91 patients, 78 were primary PMR patients and 13 were primary PS patients (Table 1).

\section{Primary PMR patients}

The majority of PMR patients $(n=73,94 \%)$ had pathology related to lower extremities while a small number of patients had problems with upper extremities $(n=5,6 \%)$. Ulcers related to amputations were the most commonly encountered clinical problem. PMR patients also presented with a number of other clinical problems (Table 2). Three patients presented with problems on the contralateral side of the amputation. Most of these were foot or toe infections and referral to the PS service was aimed at early limb salvage to prevent the patient from becoming a proximal bilateral amputee.

Surgery was not recommended for 10 patients (13\%) and treatment recommendations in this group consisted mostly of nonoperative approaches including prosthetic adjustment, adjustment of medications (including narcotics and/or neurotrophic drugs) or changes in dressing regimen. In 73 PMR patients (94\%), surgery was recommended but nine patients (12\%) declined. Most of these patients required an amputation or a revision amputation. Patients who chose to proceed with the recommended surgery had an average wait time of 4.6 months. When possible, surgical procedures such as excision of painful small lesions were performed immediately. The longest wait times, up to 14 months, were for surgical intervention of neuromas. Amputations and revision amputations were the most common procedures performed by the PS service (Table 3). Ten patients (13\%) were referred to services such as orthopedics $(n=4)$ and vascular surgery $(n=2)$ because their problem was outside the expertise of a plastic surgeon.

\section{Primary PS patients}

The number of primary PS patients referred to the combined clinic was much smaller than the primary PMR patient group. Typically, these patients had failed primary limb salvage surgery leading to amputation. Such patients were referred to the clinic for prosthetic fitting (Table 4). Prosthetics used ranged from nonfunctional cosmetic finger prostheses to functional upper limb myoelectric prostheses and various below- and
TABLE 2

Characteristics of the primary physical medicine and rehabilitation patient group $(n=78)$

\begin{tabular}{lc}
\hline & $\mathbf{n}(\%)$ \\
\hline Lower extremity pathology & $73(94)$ \\
Upper extremity pathology & $5(6)$ \\
Ulcers/chronic skin breakdown (including three patients with & $31(40)$ \\
$\quad$ wound problems on the contralateral side) & $19(24)$ \\
Neuroma/stump pain & $18(23)$ \\
Other stump problems (amputation shape, redundant skin folds, & \\
$\quad$ skin lesions, contractures, etc) & $6(8)$ \\
Joint pain (knee, ankle, foot) & $4(5)$ \\
Carpal tunnel syndrome & \\
\hline
\end{tabular}

Most patients were referred with a problem related to the lower extremity. $A$ minority of patients presented upper extremity problems. The most common problems were ulcers/chronic wound breakdown, neuroma/stump pain, and stump shape problems, together accounting for $87 \%$ of the problems

above-knee prostheses. A number of primary PS patients were seen in the clinic before amputation to discuss prosthetic rehabilitation as an alternative to limb salvage surgery.

\section{Clinical success}

PMR patients required on average three visits to the clinic, whereas PS patients had an average of two clinic visits. Because of the wide scope of problems seen in this clinic, the present study chose to use the judgment of the physiatrist, the plastic surgeon and the patient to define clinical success. Treatment failure occurred when the treatment outcome did not meet the standards of all three. In addition, patients who were in the middle of their treatment at the time of the review, patients who were referred elsewhere or patients who decided against recommended treatment were considered treatment failures. According to these strict criteria, 41 of 78 primary PMR patients (53\%) and 10 of 13 PS patients (77\%) had their presenting clinical problem solved (Table 4) by the combined clinic at the time of the review. The patients classified as treatment failures are subclassified in Table 4.

\section{DISCUSSION}

This descriptive audit provides an analysis of the first PS and PMR combined clinic designed to deal with amputees. At the treatment centre, both senior authors had been involved with the care of amputee patients for many years and referrals between the two services were common. However, communication was always delayed because most of the referrals took place via paper correspondence. Questions arising from the written consultations could not be discussed easily. Thus, it was thought that amputee patients would benefit from a combined PS/PMR consultation for the evaluation of complex problems. From reviewing the literature, it appeared that collaboration was uncommon. One example features the collaboration between plastic surgeons and urologists for the treatment of spinal cord injury patients with bladder problems and pressure sores (1).

Combined specialty clinics are most easily established in a tertiary university centre than in a peripheral private practice. Combined clinics provide unique benefits to the patient when treatment modalities for the presenting problems are complex and decisions regarding treatment involve judgment 
TABLE 3

Treatment of primary physical medicine and rehabilitation patients $(n=78)$

\begin{tabular}{lr}
\hline Treatment & $\mathbf{n ~ ( \% )}$ \\
\hline Nonsurgical treatment & $30(38)$ \\
Change in dressing regimen & 10 \\
Treatment not yet initiated & 8 \\
Adjustment of medications & 8 \\
Prosthetic adjustment & 4 \\
Surgery recommended but declined by patient & $9(12)$ \\
Revision of amputation & 4 \\
Lengthening of Achilles tendon & 1 \\
Joint release & 1 \\
Neuroma rerouting & 1 \\
Free flap resurfacing & 1 \\
Carpal tunnel release & 1 \\
Surgery performed & $29(37)$ \\
Revision amputation & 13 \\
Neuroma rerouting & 11 \\
Carpal tunnel release & 3 \\
Lesion excision & 1 \\
Achilles tendon lengthening & 1 \\
Referral to other clinical service & $10(13)$ \\
\hline Approxis
\end{tabular}

Approximately one-third of patients were considered nonsurgical patients, whereas approximately one-half of patients were thought to be surgical candidates requiring procedures within the surgical expertise provided in this clinic. A number of patients declined surgery based on risk/benefit ratio considerations. Approximately one-third of patients underwent surgical treatment through the clinic. Ten patients required expertise that was not available through the clinic and were referred elsewhere

from different specialties. This is certainly the case in one of the more common presenting problems - painful stumps. Painful stumps can be devastating to the quality of life of the patient. Often, pain in amputation stumps prevents use of a prosthesis, leading to decreased mobility and a failure to return to normal activities. In addition, the psychosocial sequelae of pain acts as a strong barrier to rehabilitation and social adaptation. Stump pain is described as burning, gnawing or as a dull ache. These symptoms may be indicative of prosthetic misfit, early pressure ulceration, neuromas, regional pain syndromes, phantom limb pain or a combination of all of these. There are a multitude of operative and nonoperative approaches to pain treatment in these patients. Nonoperative approaches are usually directed at inhibiting nerve growth. This has been attempted with alcohol, steroids, formalin, pepsin, nitrogen mustard, hydrochloric acid and phenol injections into the nerve injury site (2). An approach showing promise but not yet in clinical use is the inhibition of neurotrophic factors (3). Surgical strategies include transposition, ligation, and embedding the nerve end in bone or muscle and capping the nerve with silicone (2). In our patient population, the preferred surgical practice was a combination of nerve rerouting, internal neurolysis and loop anastomosis. The theory behind this surgery is that looped axons will experience a decrease in growth (4). This has been postulated to result from a decrease in neurotrophic factors reaching the nerve endings along with a decrease in axoplasm flow which reduces protein synthesis (5). Almost all patients who underwent surgery experienced symptomatic relief. However, several patients who received surgery
TABLE 4

Outcome of primary physical medicine and rehabilitation (PMR) and plastic surgery (PS) patients

\begin{tabular}{lc}
\hline PMR patients ( $\mathbf{n}=\mathbf{7 8}$ ) & $\mathbf{n ~ ( \% )}$ \\
\hline Problem solved as judged by patient and physicians & $41(53)$ \\
Awaiting surgery or treatment in progress & $10(13)$ \\
Patient declined surgery or chose alternative treatment & $9(12)$ \\
Unsuccessful surgery & $6(8)$ \\
Patient not fit for surgery & $1(1)$ \\
Patient expired before treatment completion & $1(1)$ \\
Treatment elsewhere & $10(13)$ \\
PS patients (n=13) & \\
\hline Problem solved as judged by patient and physicians & $10(77)$ \\
Decided against amputation & $2(15)$ \\
Patient expired before treatment completion & $1(8)$ \\
\hline
\end{tabular}

Treatment success was narrowly defined as in the text and treatment failures were analyzed and further subclassified

went on to have symptom recurrence, indicating this procedure has a failure rate. In our clinic, such patients had the benefit of a nonsurgical opinion.

The clinic also treated a large number of patients with prosthetic fit problems. These problems were usually easily solved by excision of redundant skin or rearrangement of soft tissues around the stump site. Unusual problems included a patient who presented with equinovarus deformity and an ulcer on the affected limb after a forefoot amputation. In this case, the Achilles tendon was lengthened and a free flap provided enough soft tissue coverage to reinstitute proper form to the extremity.

The success rate of $53 \%$ in the primary PMR patient group seemed relatively low. However, closer analysis of this patient group (Table 4) shows the strict criteria to define success may have been the major reason for this lower number. Therefore, the success rate likely underestimates the true contribution of this clinic. Conversely, the high success rate among PS patients (77\% success rate) may represent the fact that they are at the beginning of their amputee care and have not had sufficient time to discover problems associated with their amputation stump or prostheses.

An acquired amputation can be a devastating experience. Recent research in the rehabilitation literature has focused on amputation-related quality of life adjustment predictors such as perceived social stigma and body image (6). The adjustment required to adapt to the loss of a limb is a complicated psychological phenomenon beyond the scope of this review. Briefly, the ability to find positive meaning or have positive coping strategies (7) has been shown to be the strongest nonmedical factor influencing adaptation to amputation. In our patient group, there was a significant number of patients who declined surgery. When surgery was declined, it was ususally a proximal amputation. The present review did not address the cognitive, psychological and emotional factors that may have been involved in the patient's decision-making process. Further investigation of patients who decline amputation, even when it is considered to be warranted, is essential to gaining insight into the psychological obstacles these patients feel they must overcome. In this facet, combined specialty clinics may serve a 
purpose beyond the individual contributions of the specialists. Having two clinical appraisals of the same interaction may serve to delineate a more suitable treatment strategy and direct further clinical and basic science research.

The present review represents a critical appraisal of a novel clinic combining PMR and plastic surgery. This is an unusual combination of specialty care that facilitates interdisciplinary communication and improves patient care. Future work in this clinic may involve more in-depth analysis of our patients with the use of standardized measures of perceptions of patients who face loss of limbs.

\section{REFERENCES}

1. Sterbis JR, Lewis VL, Bushman W. Urologic and plastic surgical collaboration for continent diversion when urine leakage is complicated by pressure ulcers or obesity. J Spinal Cord Med 2003;26:124-8.
2. Rybarczyk BD, Nyenhuis DL, Nicholas JJ, Schulz R, Alioto RJ, Blair C. Social discomfort and depression in a sample of adults with leg amputations. Arch Phys Med Rehabil 1992;73:1169-73.

3. Kryger GS, Kryger Z, Zhang F, Shelton DL, Lineaweaver WC, Buncke HJ. Nerve growth factor inhibition prevents traumatic neuroma formation in the rat. J Hand Surg [AM] 2001;26:635-44.

4. Gallagher P, MacLachlan M. Positive meaning in amputation and thoughts about the amputated limb. Prosthet Orthot Int 2000;24:196-204.

5. Lewin-Kowalik J, Marcol W, Kotulska K, Mandera M, Klimczak A. Prevention and management of painful neuroma. Neurol Med Chir (Tokyo) 2006;46:62-7. (Discussion in 2006;46:67-8).

6. Low CK, Chew SH, Song IC, Ng TH, Low YP. End-to-side anastomosis of transected nerves to prevent neuroma formation. Clin Orthop Relat Res 1999:327-32.

7. Ochs S, Hollingsworth D. Dependence of fast axoplasmic transport in nerve on oxidative metabolism. J Neurochem $1971 ; 18: 107-14$ 